\title{
De la Pasión a la revolución. Kazantzakis reinterpretado por Dassin ${ }^{1}$
}

\section{From Passion to Revolution. Kazantzakis Reinterpreted by Dassin}

\author{
AMOR LÓPEZ JIMENO \\ Universidad de Valladolid \\ amor@fyl.uva.es \\ ORCID ID: 0000-0002-0136-9091
}

\begin{abstract}
Resumen: Jules Dassin fue el primero en llevar al cine una novela de Kazantzakis, Cristo de nuevo crucificado. La autora realiza un análisis contrastivo de ambas obras y la trayectoria artística de sus respectivos creadores.
\end{abstract}

Palabras clave: novela griega, cine, Nikos Kazantzakis, Jules Dassin.

\begin{abstract}
Jules Dassin was the first filmmaker to adapt a novel by Kazantzakis, Christ Recrucified. This paper presents an analysis that contrasts both of these works and the artistic careers of their respective creators.
\end{abstract}

Key Words: Greek novel, cinema, Nikos Kazantzakis, Jules Dassin.

${ }^{1}$ Este trabajo ha sido realizado dentro del Proyecto de Innovación Docente (PID) la Universidad de Valladolid Materiales audiovisuales sobre el mundo griego: elaboración y análisis, y del Proyecto de Investigación subvencionado por la Junta de Castilla y León Materiales lúdicos para el aprendizaje pragmático de segundas lenguas (español, griego, italiano, inglés, alemán). 


\section{Cristo de nUeVo cRucificado}

Kazantzakis era ya un autor consagrado internacionalmente cuando publica su segunda novela, Cristo de nuevo crucificado (O Jristós xanastavrónete), en 1948. Como la anterior, Vida y andanzas de Alexis Zorba (Bíos ke politía tu Alexi Zorbá), obtuvo un considerable éxito y fue inmediatamente traducida, primero al noruego y alemán (1951 como Pasión griega, título inicial de la obra), después al inglés (Nueva York, 1953), español (Buenos Aires), sueco, francés, y así hasta 52 lenguas en 1986. En Grecia, sin embargo, no se editó hasta 1954, desatando, de nuevo, la polémica. Pronto se hicieron adaptaciones teatrales: en Oslo en 1954 y en Atenas en 1956, con Manos Katrakis $^{2}$ de protagonista, e incluso una ópera del compositor checo Martinư ${ }^{3}$, The Greek Passion (en checo Řecké pašije), que se estrenaría póstumamente ${ }^{4}$.

La acción se sitúa en Likóvrisi, una aldea de Anatolia en la que los griegos se ven obligados a vivir bajo el dominio turco, poco antes de la Gran Catástrofe de 1922, que supuso la expulsión de los griegos de Asia Menor. Un drama que Kazantzakis había conocido de primera mano cuando tuvo que ocuparse de la repatriación de los griegos atrapados por la Revolución Rusa, en 1919. Pero no escribe una novela sobre las penalidades de su pueblo bajo los turcos ${ }^{5}$, que había vivido en carne propia en su infancia. Lo que quiere reflejar es el comportamiento entre los propios griegos en un momento de grave crisis. Likóvrisi ilustra cómo algunos contemporizaban con el poder turco, ayudando así a mantener el statu quo. Un punto de vista alejado del victimismo oficial que, como era de esperar, levantará ampollas en Grecia, cuya herida por la pérdida de Asia Menor supura incluso a día de hoy. El gobierno otomano había permitido a las minorías conservar sus señas de identidad: lengua, costumbres y religión. Los griegos de Likóvrisi se disponen, pues, a celebrar su fiesta grande, la Pascua, con una representación dramatizada de la Pasión de Cristo, como hacen cada siete años. El pope Grigoris reparte los papeles: Mijalis, el apóstol Juan; la viuda Katerina, María Magdalena; y Manoliós, un pastor retraído y tartamudo, encarnará al propio Cristo. Este es el comienzo de la novela. Entonces aparecen buscando asilo los habitantes de una aldea arrasada por los turcos,

${ }^{2}$ Manos Katrakis (1908-1984), uno de los actores más prestigiosos del teatro y cine griegos. Debutó en la época del cine mudo y después protagonizó títulos emblemáticos como Marinos Kontaras (1948) y Antigoni (1961) de Yorgos Tzavellas, Synoikia to Oneiro (1961) de Alekos Alexandrakis, Electra (Elektra, 1962) de Michael Cacoyannis y Viaje a Cythera (Taxidi sta Kythira, 1984) de Theo Angelopoulos, poco antes de fallecer.

${ }^{3}$ Bohuslav Martinů (Polička, Bohemia, 1890-Liestal, Suiza, 1959).

${ }^{4}$ En la Ópera de Zúrich el 9 de junio de 1961. En España, se estrenó en el Gran Teatre del Liceu en 1972; desde entonces, no se ha vuelto a representar.

${ }^{5}$ Muchos de los escritores griegos originarios de Asia Menor, como Ilias Venezis o Yorgos Seferis, reflejaron en sus obras el dolor por la patria perdida o sus vivencias como prisioneros. 
en castigo por haber acogido al ejército griego de liberación. Lejos de solidarizarse con sus compatriotas, el pope Grigoris y los notables de Likóvrisi se niegan a acogerlos, temiendo una represalia similar. Pero el resto del pueblo, contagiado del espíritu evangélico, ayuda a escondidas a los desterrados, apostados en los alrededores del pueblo. Cuando el pope se entera, entra en cólera y los denuncia al agá por revolucionarios, exigiendo la cabeza de su líder, Manoliós, a quien había otorgado el papel de Jesús. Su muerte se convierte, así, en una nueva crucifixión.

Como decimos, la novela no se articula sobre la dicotomía maniquea turco-opresor frente a griego-sometido, sino sobre las disensiones internas de los griegos. No hay que perder de vista que, en esos momentos, Grecia se hallaba inmersa en una guerra civil $^{6}$. A pesar del título y de que el escenario geográfico e histórico recuerde al evangélico (un pueblo ocupado por una potencia extranjera, que teme una incipiente rebelión, la entrega del cabecilla por parte del gobernador extranjero a las autoridades locales), no se trata de una de sus obras de tema religioso, sino más bien sociopolítico. Kazantzakis no busca abrir un debate teológico, ni contraponer el cristianismo al Islam (el agá se lavará las manos como Pilatos y dejará que los griegos resuelvan sus problemas entre ellos), sino invitar a la reflexión sobre el poder, con el trasfondo de la Pasión de Cristo. De un lado están los pobres, el pueblo llano, sometido, que muestra solidaridad con sus semejantes; del otro, quienes detentan el poder, incluido el pope Grigoris, quien no duda en aliarse con el agá turco e incluso delatar a sus propios feligreses.

\section{RELIGIÓN Y POLÍTICA}

Toda la biografía de Kazantzakis está presidida por una profunda espiritualidad, aunque escapara de la ortodoxia oficial. Su aspiración era encontrar un sentido trascendente de la existencia, más allá del cuerpo y la materia. Esta inquietud le llevó desde joven a buscar refugio, junto a su amigo Sikelianós ${ }^{7}$, en el epicentro de la ortodoxia, el Monte Atos, donde conocería a Yorgos Zorbás, una persona clave en su vida y que inspiró su primera novela. Kazantzakis se empapó de lecturas místicas, tradujo la Vida

${ }^{6}$ Tras la Segunda Guerra Mundial estalla en Grecia una guerra civil (1946-1950) entre los partisanos comunistas, que habían contribuido a la derrota del nazismo, y las fuerzas gubernamentales, apoyadas por la corona, Gran Bretaña y los Estados Unidos, con el fin de impedir que el país cayera en la órbita de influencia soviética. Está considerada el primer conflicto bélico de la Guerra Fría. Finalizó con la victoria del ejército sobre los comunistas y propició la posterior entrada de Grecia en la OTAN, pero el país quedó completamente devastado.

${ }^{7}$ Ángelos Sikelianós (1884-1951). Fue el primer poeta griego propuesto para el Premio Nobel de Literatura. Con el apoyo de su esposa, la americana Eva Palmer, creó en 1927 el Festival de Delfos, con representaciones en el antiguo teatro, para impulsar el renacimiento de la "Idea Délfica". 
de San Francisco de Johannes Jörgensen ${ }^{8}$, se asomó al budismo. Su sentimiento religioso está fuera de toda duda, pero chocaba con la jerarquía eclesiástica, de ahí que recibiera con gran dolor la propuesta de excomunión, en 1955, tras la aparición de La última tentación (O Teleftéos Pirasmós). Su fe no es convencimiento sin fisuras, sino anhelo, deseo de creer. Indaga, estudia, no cierra ninguna puerta. Su producción literaria atestigua esa búsqueda incansable: Monte Atos (1914), Ejercicios espirituales (1927, redactados en Berlín en 1923), Ascética (1927), las tragedias Cristo (1928) y Buda (1956), La última tentación (1951), El pobrecillo de Asís (1956, dedicada a San Francisco), sendos poemas a Cristo y a Santa Teresa, Informe al Greco (1957). Incluso sus reportajes de prensa y sus libros de viajes (serie Viajando, desde 1926 a 1939), obedecen a veces a razones de índole religiosa. Este es el motivo, por ejemplo, de ir a Toledo tras las huellas de su paisano, El Greco. No es solo admiración por su arte, sino sobre todo por su pasión (pathos):

Solo con una fugaz mirada a sus cuadros, de brillantes colores y personajes pálidos, consumidos por un fuego interior, sentí que me quedaba sin respiración [...]. Con todos los apóstoles a mi alrededor, me siento de repente como rodeado por las llamas [...] En todos los cuadros de El Greco la luz desgarra violentamente la atmósfera $[\ldots]$ consume los cuerpos, borra los límites entre cuerpo y alma, tensa los cuerpos como un arco a punto de romperse. Su luz es movimiento. Movimiento violento [...]. El anhelo de El Greco es encontrar lo esencial más allá de la apariencia; dominar el cuerpo, estirarlo, envolverlo en luz e incendiarlo [...]. Los retratos de El Greco tienen tal poderío que te estremecen, como si vieras aparecer en la oscuridad al viejo caballero o al cardenal como un fantasma. Para El Greco el cuerpo humano era un obstáculo, pero a la vez el único modo de manifestarse el alma $[\ldots]$. Cuando contemplas sus retratos, te invade un temor metafísico [...]. El arte recupera así su fuerza mágica primigenia de revivir a los muertos. Pero estos cuerpos resucitados carecen de dulzura, naturalidad y calor humano. Han pasado por el Infierno, el Purgatorio y el Paraíso, y regresan a la tierra como llamas sobrenaturales (Kazantzakis, 1961: 88-91) ${ }^{9}$.

De igual manera, su fascinación por la mística y, concretamente, por Santa Teresa, le llevan a Ávila:

Pienso en esta maestra del éxtasis, que unió en su persona en perfecta simbiosis a de Don Quijote y Sancho [...] La fe, incluso la más ascética, ha sido siempre la mejor y más fecunda vía de vivir intensamente la vida, no solo la del más allá, sino también ésta terrenal. Solo gracias a la fe pueden elevarse las masas ¿qué quiere decir "elevarse"? someter sus deseos y

\footnotetext{
${ }^{8}$ Johannes Jorgensen (1866-1956), autor danés, convertido al catolicismo. En una visita a Asís, en 1894, se despertó su admiración por San Francisco, a quien dedicó una biografía en 1907.

${ }^{9}$ Las traducciones, salvo indicación contraria, son propias.
} 
exigencias individuales a un orden humano más profundo (Kazantzakis, 1961: 55).

Pero, si tiene un alma gemela en España es, sin duda, Unamuno, con quien comparte ese deseo de creer mezclado de angustia, esa búsqueda de lo absoluto, incluso su «sentimiento trágico de la vida». Ambos se encontraron varias veces, la última, recién comenzada la Guerra Civil, poco antes de la muerte del español:

Todo esto sucede porque los españoles no creen en nada. ¡En nada! ¡En nada! Están desesperados ${ }^{10}$. Ningún otro idioma del mundo posee esta palabra, porque ningún otro pueblo posee este concepto, sólo el español. Desesperado se refiere al que sabe que no tiene ya nada que perder, que ya no cree en nada y por tanto, sin fe, está lleno de rabia (Kazantakis, 1961: 156-157).

Si hay un término griego que identifica a todos los héroes de Kazantzakis, reales y literarios, es pathos, pasión, deseo, anhelo, sufrimiento. Pathos es la desbordante energía vital de Zorba. Pathos es también lo que empuja a Odiseo a viajar sin descanso. Incluso su creación literaria es más una experiencia espiritual que estética, como desvela a menudo en sus cartas a su amigo Prevelakis ${ }^{11}$. Y la Pasión (ta Pathi, en griego) es el pretexto de Cristo de nuevo crucificado para recuperar la esencia del cristianismo, el verdadero mensaje de Cristo, su humanidad, su sacrificio, frente a las jerarquías eclesiásticas y su ejercicio del poder. A través de la Pasión reivindica el Evangelio y la iglesia de los pobres, encarnada en el pope Fotis y su grey, frente a la Iglesia institucional, personificada en el pope Grigoris, que no duda en aplastar la disidencia con tal de mantener su status de autoridad. Lo sufre Manoliós en la novela y lo sufrió Kazantzakis en la vida real.

Cuando surgió el comunismo, muchos lo compararon con el cristianismo primitivo. Kazantzakis también se sintió atraído por la figura de Lenin, que, en su momento, fue recibido como un nuevo mesías, portador de liberación, justicia social y solidaridad internacional, sueño que pronto tornaría en desilusión. Kazantzakis viajó a Rusia y participó activamente en la repatriación de los refugiados griegos del Cáucaso: pudo ver in situ las consecuencias de la Revolución. La esperanza inicial de libertad y regeneración pronto chocó con la realidad. Aunque a menudo se le señala como (filo)comunista, él mismo lo negó categóricamente y rechazó la dictadura del proletariado, como cualquier otra forma de represión. Si hay algo imposible, es encasillar a Kazantzakis bajo cualquier etiqueta. Su

${ }^{10}$ En español en el original.

11 Pantelís Prevelakis (Rethimno, 1909-1986), escritor y amigo íntimo de Kazantzakis. Escribió la trilogía El cretense (1948-1950), sobre los levantamientos de la isla en el siglo XIX, y Los caminos de la creación (1959-1966), autobiográfica. Su intercambio epistolar es una fuente importantísima para conocer a Kazantzakis. 
personalidad era poliédrica, compleja, en absoluto monolítica. De lo que no cabe duda es de que la Revolución Rusa cambió el curso de la Historia. Muchos jóvenes se sintieron cautivados por las promesas de cambio y libertad y el comunismo se extendió por todo el mundo. Uno de estos jóvenes fue el americano Jules Dassin.

\section{JULES DASSin, ASCENSO Y CAÍdA EN HOLLYWOOD}

Julius Samuel Dassin nació en 1911 en Middletown, Connecticut, Estados Unidos, en una familia judía de emigrantes rusos, y creció en el Harlem neoyorquino, un barrio marginal que sufriría con especial crudeza la Gran Depresión. En ese entorno deprimido despertará muy pronto su conciencia social y descubrirá el teatro, gracias al Arbeter Teater Farband (ARTEF), una compañía socialista judía. Como muchas otras víctimas de la crisis, se afilió al Partido Comunista, que abandonaría en 1939, decepcionado por el pacto de Stalin con Hitler. Pese a ello, esta breve militancia marcará más tarde su destino.

Empezó escribiendo guiones para la radio y el teatro. En Broadway llama la atención de un cazatalentos de Hollywood, y en 1940 se traslada a California. Empieza a trabajar en la RKO como ayudante de dirección de Alfred Hitchcock. Debuta como director en la MGM, con una adaptación de El corazón delator de Edgar Allan Poe, el cortometraje The Tell-Tale Heart (1941), que obtuvo un sorprendente éxito $^{12}$. Le ofrecen entonces un contrato de siete años que, a la larga, se convertirá en una pesadilla: los estudios eran famosos por su star system y todo estaba enfocado a resaltar a las estrellas. El director carecía de autoridad y libertad creativa, ni siquiera controlaba el montaje y, en consecuencia, el resultado final. Amarrado por un contrato leonino, se vio obligado a dirigir siete largometrajes con irregular fortuna, de los que no se consideraba responsable: Nazi Agent (1942), Reunión en Francia (Reunion in France, 1942), The affairs of Martha (1942), Young Ideas (1943), El fantasma de Canterville (The Canterville Ghost, 1944), A Letter for Evie (1946) y Two Smart People (1946).

Una vez liberado de la MGM, entró en la Universal, donde el sistema de trabajo era completamente diferente. Mark Hellinger ${ }^{13}$ trasladó su gusto por el realismo y las historias cotidianas a la producción, especializando a la Universal en el género negro y de gánsteres. Gracias a la libertad de acción y

12 Jules Dassin (1941), El corazón delator (The tell-tale heart) [cortometraje] [en línea: https: //youtu.be/hAV56Lv6fdg. Fecha de consulta 21/02/2020].

${ }^{13}$ Mark Hellinger (1923-1947) fue un prestigioso crítico teatral y guionista. Pasó a la producción de la mano de Jack Warner, hasta independizarse y convertirse en el hombre fuerte de la Universal. Como productor se especializó en el género negro y de gánsteres. Imprimía a sus historias un sello realista y marcado por las preocupaciones sociales, por lo que sintonizó bien con directores como Dassin, Raoul Walsh o John Huston. 
el apoyo de Hellinger, Dassin pudo, por fin, demostrar su talento en dos películas revolucionarias: Fuerza bruta (Brute Force, 1947) y La ciudad desnuda (The Naked City, 1948).

En Fuerza bruta podemos, pues, ver al verdadero Jules Dassin, sus gustos y preocupaciones sociales. Lejos del glamour del star system de la Metro, no solo hace protagonistas a unos presidiarios, sino que, además, destaca sus virtudes: la solidaridad, la defensa del débil, la rebelión ante la injusticia, el sacrificio, mientras los representantes de la autoridad se distinguen por la corrupción y el sadismo. En esta obra están ya presentes argumentos y rasgos de estilo que se repetirán a lo largo de su filmografía: temas como la justicia y el abuso de autoridad, la rebeldía y el uso de la violencia, el valor de la amistad y la solidaridad, el "heroísmo" y la traición, y un gusto por el realismo, por reflejar la vida cotidiana y la gente corriente. Dadas las circunstancias posteriores, Fuerza bruta es la única película de su etapa americana en la que Dassin trabajó con plena libertad, lo que la hace especialmente valiosa para analizar su cine.

En un entorno radicalmente opuesto, La ciudad desnuda sigue, sin embargo, el mismo patrón. Aunque es una película policíaca, es muy distinta a las típicas del género. Dassin había quedado impactado por Roma, ciudad abierta (Roma, città aperta, 1945) y, como Rossellini, saca la cámara a la calle y refleja la palpitante vida de la ciudad, Nueva York, verdadera protagonista de la cinta, y sus habitantes, pero no la clase alta, sino los de los barrios que Dassin bien conocía. Gracias a ella se le considera el padre del neorrealismo americano. Por desgracia, la repentina y prematura muerte de Hellinger puso fin no solo a una fructífera colaboración, sino también a su control sobre el montaje final: las listas negras habían empezado a circular y los nuevos ejecutivos del estudio eliminaron cuanto pudiera interpretarse como "propaganda comunista".

Al año siguiente dirige Mercado de ladrones (Thieves' Highway, 1949), para la 20th Century Fox, sin sospechar que sería su último rodaje en su país. Efectivamente, en los años 50 arrecia la infame "Caza de Brujas" del senador McCarthy, y el Comité de Actividades Antiamericanas (HUAC) persigue a toda persona sospechosa de comunismo, pisoteando los derechos consagrados en la Constitución. La industria cinematográfica, por su potencial influencia en la opinión pública, pronto estuvo en el punto de mira del Comité y los propios estudios se prestaron al juego, por miedo a perder sus pingües ingresos, elaborando sus propias listas negras. Así se impusieron los despidos, las traiciones y la autocensura en Hollywood. Dassin fue 
delatado al HUAC por Edward Dmytryk ${ }^{14}$ y Frank Tuttle ${ }^{15}$, y el productor Darryl F. Zanuck ${ }^{16}$ le envió a Londres a rodar Noche en la ciudad (Night and the City, 1950), que sería su última película americana. Aunque no llegó a declarar ante el Comité, porque las audiencias se suspendieron, se le cerraron las puertas de Hollywood y, como otros muchos, tuvo que marchar al exilio, instalándose en París.

Sus comienzos en Europa tampoco fueron fáciles. Las presiones americanas frustraban cada proyecto que emprendía. La protagonista de $E l$ enemigo público número uno (L'ennemi public no 1 , Henri Verneuil, 1953), Zsa Zsa Gabor, forzó su despido poco antes de comenzar el rodaje, desencadenando el famoso "affaire Dassin": el sindicato francés, indignado por la intromisión de los Estados Unidos en los asuntos internos del país y la retirada de la nacionalidad a Dassin, lo nombró miembro de la Unión Francesa de Directores. No le sirvió, sin embargo, para evitar el boicot en otros países. En Italia vio naufragar diversos proyectos e incluso cuando estaba a punto de rodar, los Estados Unidos exigieron su expulsión del país.

Desesperado por la falta de trabajo, en 1955 acepta el encargo de adaptar la novela Du rififi chez les hommes (1953), de Auguste Le Breton ${ }^{17}$. Escrita en argot, decidió limitarse al único pasaje que logró entender y construir la película en torno a él, un atraco. El exiguo presupuesto le obligó a recurrir a actores de segunda fila, como Jean Servais y él mismo ${ }^{18}$, y eliminar la banda sonora. Sorprendentemente, este silencio aumenta la tensión en la escena clave del robo, uno de los momentos antológicos de la Historia del Cine. Rififi es uno de los clásicos del género y ha servido de modelo a otros filmes de $\operatorname{atracos}^{19}$, además de uno de los éxitos más grandes de su carrera. Con el embargo aún vigente, para su distribución en Estados Unidos exigieron

${ }^{14}$ Edward Dmytryk (1908-1999), director de origen ucraniano y uno de los "Diez de Hollywood". Convocado por el HUAC, inicialmente se negó a cooperar, pero, tras varios meses en prisión, cedió y reconoció su breve pertenencia al Partido Comunista, delatando a 26 compañeros. Posteriormente se exilió en Reino Unido, desde donde siguió trabajando para los grandes estudios.

${ }^{15}$ Frank Tuttle (1892-1963), su carrera se fue al traste cuando fue citado como testigo por el HUAC y reconoció su antigua afiliación comunista, denunciando a algunos camaradas.

${ }^{16}$ Darryl F. Zanuck (1902-1979), uno de los productores más importantes del Hollywood glorioso, con un especial olfato para el éxito. Fundó la 20th Century Fox, en la que ejercía un control absoluto de todo el proceso de producción.

${ }^{17}$ Pseudónimo de Auguste Montford (1913-1999), autor de novelas policiacas.

${ }^{18}$ Siempre fue consciente de sus limitaciones interpretativas. Aquí encarna al chivato de la banda, César, "el milanés”, bajo el pseudónimo de Perlo Vita.

19 "Rififi" pasó a denominar cualquier robo por el método del butrón. Poco después Jacques Deray rodaría Rififí en Tokyo (Rififi à Tokyo, 1963), basada en otra novela de Le Breton. En Italia se hicieron dos parodias, Rufufú (I soliti ignoti, Mario Monicelli, 1958) y Rufufú da el golpe (Audace colpo dei soliti ignoti, Nanni Loy, 1959), con Marcello Mastroianni, Totò, Claudia Cardinale y Vittorio Gassman. El propio Dassin se autoparodiará en Topkapi (1964). 
omitir su nombre, a lo que se negó, por lo que el filme solo pudo exhibirse en salas alternativas. Aun así, fue el primero en desafiar las listas negras ${ }^{20}$. La película no solo le devolvió su prestigio, con el Premio al Mejor Director en el Festival de Cannes de 1955, sino que además propiciaría un nuevo giro en su vida. En Cannes conoce a Melina Mercouri y se irá a vivir con ella a Grecia.

Para la mayoría de los críticos, el brillante director de cine negro sacrificó su talento para impulsar la carrera de su mujer, y su carrera posterior no alcanzará las cotas anteriores, aunque aún engendrará éxitos considerables, como Nunca en domingo o Topkapi $i^{21}$. Pero, a la hora de juzgar, hay que tener en cuenta en primer lugar las diferencias entre el cine europeo y el americano y, sobre todo, la diferencia abismal entre la poderosa maquinaria productiva de los estudios de Hollywood y la precaria infraestructura cinematográfica de la Grecia de posguerra. En vez de recibir encargos y ofertas, tendrá que buscar él mismo financiación, escribir el guion, dirigir y, a veces, interpretar, a la manera de un "autor" al estilo europeo, bregando siempre con la precariedad económica. Por otra parte, es de justicia recordar que el propio género negro quedó herido de muerte por la "Caza de Brujas". Dassin tuvo que empezar de cero en Grecia y, aunque los resultados fueron irregulares, no hay que restarle el mérito de reinventarse una y otra vez, en un camino plagado de contratiempos. El primero se presentó cuando se plantearon trasladar a la gran pantalla la exitosa novela Vida y andanzas de Alexis Zorba, de Nikos Kazantzakis, a quien conoció en el sur de Francia a través de Melina. Pero Dassin se empeñó en reclamar como protagonista a Nikolai Cherkasov ${ }^{22}$, miembro del Partido Comunista de la URSS, un escollo insalvable en plena Guerra Fría, y el proyecto no cuajó ${ }^{23}$. Eligieron entonces otra obra, Cristo de nuevo crucificado, que será la primera de las tres novelas de Kazantzakis en llevarse a la gran pantalla, con el título de Celui qui doit mourir (El que debe morir, 1957), con Melina Mercouri, Pierre Vaneck y, de nuevo, Jean Servais como cabezas de cartel. En la adaptación del guion colaboró el también represaliado Ben Barzman $^{24}$.

${ }^{20}$ Mérito general pero erróneamente atribuido a Dalton Trumbo (1905-1976), otro de los "Diez de Hollywood", acreditado como guionista en Espartaco (Spartacus, Stanley Kubrick, 1960), pero cinco años después.

${ }^{21}$ Remitimos para un análisis pormenorizado a la monografía de López Jimeno (2012).

22 Nikolai Cherkasov (1903-1966), actor fetiche de Sergei M. Eisenstein, protagonizó sus películas Alexander Nevsky (Aleksandr Nevskyi, 1938), Iván el Terrible (Ivan Groznyy, 1944) e Iván el Terrible, segunda parte: la conjura de los boyardos (Ivan Groznyy. Skaz vtoroy: Boyarskiy zagovor, 1958).

${ }^{23}$ Finalmente la rodaría Michael Cacoyannis, años después, como se refiere en artículo de Alejandro Valverde García en este monográfico.

${ }^{24}$ Ben Barzman (1911-1989), guionista de origen canadiense. Militante del Partido Comunista, como su esposa, la actriz y escritora Norma Barzman, al ser 


\section{EL QUE DEBE MORIR, PUNTO DE INFLEXIÓN}

Aunque la película es de producción francesa, era absolutamente impensable, en 1957, rodar en Anatolia, dadas las tensas relaciones de Grecia con Turquía ${ }^{25}$. Tampoco en Grecia iban a extender la alfombra roja para que se filmara una obra del exiliado Kazantzakis, pero en su Creta natal aún gozaba de respeto, de modo que decidieron llevar el rodaje allí, una vez que Dassin consiguiera un pasaporte. El padre de Melina, Stamatis Mercouris $^{26}$, medió para que pudiera viajar.

Así pues, Dassin se dispuso a buscar localizaciones en Creta, con ayuda de su director artístico, Alexander Trauner ${ }^{27}$, con quien acababa de hacer Rififi, pero no contaban con la sacrosanta hospitalidad griega. En un país devastado por años de guerra, un rodaje internacional representaba un honor que nadie quería dejar escapar, además de puestos de trabajo. A las deficientes infraestructuras (a muchos lugares solo podían acceder a lomos de un asno) se sumaban las recepciones oficiales en cada aldea, por diminuta que fuera. En una ocasión, Dassin, incluso, sufrió un malentendido que le hizo temer por su integridad. En pleno fragor de la crisis chipriota ${ }^{28}$, un

delatado por Dmytryk se exilió en Europa, donde siguió trabajando. Es el guionista, por ejemplo, de las superproducciones rodadas en España en los años 60 El Cid (Anthony Mann, 1961), 55 días en Pekin (55 Days at Peking, Nicholas Ray y Guy Green, 1963) y La caída del Imperio Romano (The Fall of the Roman Empire, Anthony Mann, 1964). En 1976 regresó a los Estados Unidos.

${ }^{25}$ Por culpa de la "cuestión chipriota". Si bien la isla de Chipre estaba bajo dominio británico, la población local, griegos (partidarios mayoritariamente de la unión con Grecia) y turcos, estaba inmersa en violentos enfrentamientos, demasiado similares a lo que se cuenta en la novela. Poco después (1959) Gran Bretaña concede la independencia a la isla, y el 16 de agosto de 1960 se proclama la República de Chipre, que no acaba con el conflicto. En 1974 Turquía invade la mitad norte para "proteger" a la comunidad turca, quedando la isla dividida hasta hoy.

26 Melina provenía de una familia de larga tradición política. Su abuelo, Spirídonas, fue Alcalde de Atenas, su tío, Yorgos, Presidente del Partido Nacional Socialista y su padre, Stamatis, llegó a ser diputado (1950, 1958-1967) y Ministro (1945-1946).

${ }^{27}$ Alexander Trauner (1906-1993), diseñador y uno de los mejores directores artísticos del cine, responsable, por ejemplo, de Testigo de cargo (1957), El apartamento (1960), Un dos tres (1961) e Irma la Dulce (1963) de Billy Wilder. Finalmente fue sustituido por el francés Max Douy, autor de la direccion artística de La Règle du jeu de Jean Renoir (1939), entre otras muchas.

${ }^{28}$ En la década de los 50 la situación de la isla era crítica. En enero de 1950, los chipriotas se pronunciaron mayoritariamente en referéndum a favor de la unión con Grecia, un deseo largamente acariciado. La elección de Makarios, líder político y religioso de la mayoría griega ortodoxa, como etnarca alentó dichas aspiraciones, apoyadas, lógicamente, por el gobierno de Grecia. En 1954 se presentó una petición formal ante el gobierno británico y ante la ONU, pero Gran Bretaña no quería perder su soberanía sobre la isla, dada su posición estratégica como puerta de Oriente Medio. Los turcos, por su parte, reaccionaron reclamándola para sí en 1955, abriendo una 
alcalde, que no distinguía entre ingleses y americanos, le reclamó la isla: « ¡Devolvednos Chipre!» De nada servían las aclaraciones de Dassin, hasta que le retó: «si queréis Chipre, tomadla vosotros mismos» ${ }^{29}$. La tensión se disolvió en un brindis de acogida.

Al final escogieron Kritsá, un pueblo de montaña al este de la isla, donde la presencia de tan ilustres forasteros fue un auténtico acontecimiento que todavía hoy se recuerda ${ }^{30}$. Todos sus habitantes intervinieron como figurantes y dieron lugar a numerosas anécdotas. Casi ninguno sabía leer, así que al acabar las faenas del campo cada noche se reunían en la escuela y Melina les leía el guion. El reparto no fue fácil. Nadie quería interpretar a los ricos, por más que tuvieran más papel y por tanto remuneración: eran "los malos", los insolidarios y se trataba de una cuestión de honor, un concepto sumamente importante en Creta. Si al final les convencieron de que eran imprescindibles para poner la obra en pie, con lo que no transigieron de ningún modo fue con hacer de turcos. Dassin tuvo que recurrir a los americanos de una base militar cercana. Los soldados turcos son en realidad tejanos ocultos tras unos considerables mostachos.

Agradecido por la fortuna ganada con Rififi, el productor Henri Bérard dio carta blanca a Dassin, incluso transigió con decisiones tan poco comerciales como el formato en cinemascope y la fotografía en blanco y negro. Su estreno en Cannes, el 2 de mayo 1957, al que asistió un Kazantzakis ya muy enfermo, coincidió con la muerte del senador McCarthy, pero los americanos aún evitaban aparecer fotografiados junto a Dassin y Barzman.

El que debe morir recibió varios premios internacionales ${ }^{31}$, pero no funcionó en la taquilla. Tras la muerte de Kazantzakis, y, al parecer por problemas sobre los derechos de autor, durante muchos años era prácticamente imposible de ver, lo que provocó que cayera en el olvido. Afortunadamente, hoy está editada en $\mathrm{DVD}^{32}$. Aunque no se cuente

crisis en el seno de la OTAN. En 1958 Gran Bretaña impuso una administración tripartita. Makarios, desde el exilio, renunció a la unión con Grecia y aceptó la independencia como solución intermedia. El 16 de agosto de 1960 nace la República de Chipre, dentro de la Commonwealth, con Makarios de Presidente y el turcochipriota Fazıl Küçük, de Vicepresidente.

${ }^{29}$ Contado por él mismo en la entrevista a F.Germanós de la ERT recogida en la bibliografía final, 00:16:55.

${ }^{30}$ Véase por ejemplo un programa de la televisión griega al respecto: Kritsa Melina Merkouri [en línea: https://youtu.be/BVnzRpmfdq4. Fecha de consulta $21 /$ 02/2020].

${ }^{31}$ Mención especial OCIC en Cannes, Lábaro de oro en la Semana Internacional de Cine religioso y de valores de Valladolid, Nominado a la Mejor Película en los BAFTA, Nominado a la Mejor película de habla no inglesa por el Círculo de Críticos de Nueva York.

${ }^{32}$ Distribuida en España por Blanco y Azul Canal de Distribución S.L. 
entre sus títulos insignia, esta película es imprescindible para conocer al Dassin cineasta, pues es la primera que gestó de principio (elección del tema) a fin (montaje final), como un verdadero "autor", según la definición de Truffaut y, por tanto, la más personal, aunque el guion no fuera original, sino adaptado. Él mismo siempre la consideró su favorita.

\section{FilMografíA POSTERIOR}

Entre tanto, Dassin recuperó su pasaporte y pudo regresar a su país, pero los efectos del "macartismo" tardarían en desaparecer y le fue imposible retomar su carrera en América. Tras el descalabro de Celui qui doit mourir, tuvo que volver a aceptar encargos de supervivencia. Con La ley (La legge / La loi, 1959) pudo por fin rodar en Italia. Sin embargo, la imposición de la protagonista, Gina Lollobrigida, y sus exigencias de diva le recordaron sus peores tiempos en la Metro. Ni la presencia de Yves Montand y Marcello Mastroianni consiguieron salvarla del naufragio, aunque Dassin pensaba que era el mejor guion que había escrito.

Cuando su carrera parecía enterrada, después de dos fracasos consecutivos, le llegó su mayor éxito, Nunca en domingo (Never on Sunday, 1960), título emblemático en su filmografía y en la cinematografía griega. Por necesidad, fue, además, su proyecto más personal, pues tuvo que asumir las funciones de guionista, director, productor e incluso actor ${ }^{33}$. El mensaje político que pretendía transmitir (una crítica al imperialismo americano) queda completamente eclipsado y reducido a la contraposición entre el american lifestyle, que encarna Homer (Jules Dassin) y el mediterranean lifestyle personificado en Ilya (Melina Mercouri). A años luz del cine negro que le había dado fama, Nunca en domingo es una película chispeante, luminosa, que contagia alegría de vivir, un carpe diem en celuloide. La cinta le reportó no solo un rotundo éxito de taquilla ${ }^{34}$, sino también un regreso a casa triunfal: el otrora apestado fue nominado a cinco Oscar de la Academia americana ${ }^{35}$ y, por primera vez, una canción no inglesa se llevó la estatuilla a la Mejor Canción Original (Manos Hadjidakis) ${ }^{36}$. «Los niños de El Pireo» se hizo

${ }^{33}$ Él la escribió pensando en Jack Lemmon.

${ }^{34}$ Costó apenas $151.000 \$$ y recaudó $8.000 .000 \$$.

${ }^{35}$ En las categorías de: Director y Guión Original (Jules Dassin), Actriz Protagonista (Melina Mercouri), Diseño de Vestuario (Theoni V. Aldredge) y Canción original (Manos Hadjidakis). Mercouri no consiguió el Oscar, pero esta vez sí ganó en Cannes (Premio a la Mejor Actriz).

36 Manos Hadjidakis (1925-1994), compositor de fama internacional e imprescindible en el panorama musical griego. Es autor de canciones y bandas sonoras (Stella, América, América, Sweet Movie, Topkapi) ya convertidas en clásicos. 
famosa en el mundo entero ${ }^{37} \mathrm{y}$, con permiso de «Zorba», de Theodorakis, es la melodía griega por antonomasia, reproducida hasta la saciedad ${ }^{38}$.

En lugar de abonarse al éxito seguro con secuelas de Nunca en domingo, se arriesgó a cambiar de registro y actualizar una tragedia clásica, el Hipólito de Eurípides, con Fedra (Phaedra, 1962). Pero el público no quería tragedias y le dio, de nuevo, la espalda. Retorna, pues, a la comedia con Topkapi (1964), una nueva cinta de atracos, basada en la novela The Light of Day de Eric Ambler $^{39}$, y recupera el favor de crítica y público ${ }^{40}$. El robo en el palacio del sultán, un ejercicio de ingenio y habilidad sin violencia ha servido de inspiración a otros robos en las abundantísimas películas del género ${ }^{41}$. Pero este será su último éxito. Al año siguiente rueda en España Las 10:30 de una noche de verano (10:30 P.M. Summer, 1966), sobre el relato de Marguerite Duras, y su carrera cinematográfica pasará a un segundo plano, por motivos, de nuevo, políticos.

Efectivamente, en 1967 los Coroneles dan un golpe de estado en Grecia e instauran la dictadura. La Junta retira la nacionalidad a Melina y la pareja, que estaba representando Ilya Darling en Broadway, se encuentra de repente en un exilio forzoso. Mientras ella se volcaba en recabar apoyos contra la dictadura, Dassin aprovechó la estancia en su país natal para rodar una cinta sobre los movimientos por la igualdad racial que estaban en plena ebullición (Uptight, 1968), a la que sigue Promesa al amanecer (Promise at Dawn, 1970) y un documental netamente político, The Rehearsal (1974), que no llegó a estrenarse por la caída de la Junta. Su último filme en común fue Gritos de pasión (A Dream of Passion / Kravgi gynaikon, 1978), una compleja versión

${ }^{37}$ Se han grabado versiones en francés, inglés, italiano, holandés, chino, hebreo, checo, serbio y croata. En español ha sido interpretada por Gloria Lasso, José Vélez, Los cinco Latinos, Los Españoles, el trío mejicano Los Soberanos, la cubana Xiomara Alfaro y por la italiana Dalida.

${ }^{38}$ Hasta tal punto que el propio Hadjidakis la llegó a aborrecer. Se cuenta que llegó a tirar el Oscar - ni siquiera había acudido a la Gala-a la basura y, como anécdota ilustrativa, cedió los derechos de autor por una cantidad irrisoria - el precio de arreglarse los dientes, rotos durante la guerra- dejando así escapar una auténtica mina de oro.

${ }^{39}$ Eric Ambler (Londres 1909-1998), autor de numerosas novelas negras y de espías llevadas al cine: Uncommon Danger (1937), dirigida por Raoul Walsh con el título Background to Danger (1943); Epitaph For a Spy (1938), convertida en Hotel Reserve (Lance Comfort, Mutz Greenbaum y Victor Hanbury, 1944); La máscara de Dimitrios (The mask of Dimitrios, 1939), película homónima de Jean Negulesco (1940); Journey into fear (1940), película Estambul de Norman Foster (1943). Él mismo escribió el guion de Amigos apasionados (The passionate friends, David Lean, 1950), La última noche del Titanic (A night to remember, Roy Ward Baker, 1959) y Rebelión a bordo (Mutiny on the Bounty, Lewis Milestone, 1962).

${ }^{40}$ Peter Ustinov ganó el Globo de Oro, el Laurel de Oro y el Oscar al Mejor Actor Secundario.

${ }^{41}$ En España fue parodiado por Martes y Trece en la disparatada El robobo de la jojoya (Álvaro Sáenz de Heredia, 1991). 
actualizada del mito de Medea. De vuelta en Grecia, Mercouri se dedicó a la política, como diputada por el Partido Socialista (PASOK) desde 1977 y Ministra de Cultura en el gabinete de Andreas Papandreu desde 1981 hasta su muerte en 1994.

Dassin se retira del cine tras la decepción de Círculo de dos (Circle of Two, 1980), con Richard Burton y Tatum O' Neal, para centrarse en el teatro y, sobre todo, tras la muerte de su mujer (1994), en la Fundación Melina Mercouri y su labor filantrópica. Prosiguió la campaña de su mujer por la recuperación de los mármoles de la Acrópolis de Atenas que Elgin vendió al Museo Británico e impulsó la construcción del Nuevo Museo de la Acrópolis.

\section{Del Cristo mártir de Kazantzakis al Cristo agitador de Dassin}

Aunque Cristo de nuevo crucificado fue la única de sus novelas que alcanzó a ver en la pantalla, Kazantzakis no intervino en el guion, que elaboró Dassin con ayuda de Ben Barzman. Es evidente que trasladar a lenguaje cinematográfico una obra literaria tan compleja requiere algunos sacrificios, $\mathrm{y}$, en consecuencia, las partes más puramente literarias (como los monólogos, las reflexiones del autor, los sueños, las lecturas del Evangelio, diálogos demasiado largos, algunos pasajes y personajes secundarios) fueron reducidas o directamente suprimidas, conservando la acción, los diálogos y cuanto podía ser contado en imágenes, como las descripciones y la psicología de los personajes. Por naturaleza, un texto fílmico tiene más recursos de expresión que una novela, porque al elemento verbal se suman varios componentes extralingüísticos: gestualidad y movimiento, imagen, banda sonora. Dassin ha construido la película siguiendo el modelo narrativo clásico, respetando el discurso lineal de la novela. Estéticamente, la elección del blanco y negro y su estilo, cercano al neorrealismo, le confieren apariencia de documental y verosimilitud.

La película arranca con el incendio de una aldea y la forzosa partida de sus habitantes, capitaneados por su pope, Fotis (Jean Servais); una escena añadida por Dassin, que sirve de prólogo, mientras se suceden los títulos de crédito. Inmediatamente cambia de escenario y tono: nos traslada a otra aldea, en la que vemos a un agá (Grégoire Aslan) fumando su cachimba y una muchacha que canta en turco, mientras unos griegos se acicalan para una fiesta. A diferencia de la primera aldea, en esta, cuyo nombre nunca se menciona, reina la paz entre griegos y turcos. Pero, con otro cambio de escenario, nos saca del error: el maestro en la escuela presagia la pronta liberación del yugo otomano, con el paralelismo de la victoria sobre los persas en Maratón. El diálogo entre Patriarqueas (Gert Fröbe) y el agá verbaliza la situación de sometimiento en que viven los griegos: Patriarqueas pide permiso para representar la Pasión de Cristo, como hacen cada siete años. El agá lo concede con desdén y las campanas repican con regocijo, convocando a los fieles. Reunidos todos en la iglesia, el pope, Grigoris (Fernand Ledoux), desde el ambón (con un magnífico plano picado 
posterior que recalca su posición de poder) señala a los seleccionados para el auto sacramental. Así, con una hábil alternancia de planos y escaso dialogo, el director resuelve en los primeros minutos toda la introducción del libro, presenta los personajes principales y sitúa al espectador en el contexto espacio-temporal de la historia.

Dassin plantea la película como una obra coral, de ahí que abunden los planos generales con numerosos figurantes, subrayando el sentido de comunidad. La elección no es casual y, sin duda, tiene que ver con la intención del cineasta y el mensaje ético y político implícito, del que hablaremos después. No pueden faltar, obviamente, escenas de diálogo entre los personajes más destacados: el agá y el jerarca de los griegos, Patriarqueas, Katerina y Manoliós, o Manoliós y el pope Grigoris, por citar algunas.

La escenografía y el vestuario no se utilizan como mero soporte decorativo, por el contrario, contienen información implícita para identificar a los personajes y marcar su posición en la comunidad:

a) El agá, rodeado de lujos y placeres en su mansión (manjares, sirvientes, mujeres): representante de la autoridad.

b) Patriarqueas, con una buena casa, la despensa llena, buenos muebles y trajes elegantes: el (griego) rico del pueblo.

c) La aldea, con su fuente, la iglesia, la escuela, el barbero, carros, casas de piedra, el fuego encendido, ganado, y sus habitantes, bien vestidos, calzados: pruebas de su relativa prosperidad.

d) La montaña desnuda, los refugiados, acampados a la intemperie, descalzos, harapientos, con objetos simbólicos (el icono, los huesos de los antepasados) como únicas pertenencias: pobreza extrema, desarraigo.

Con la aparición de estos últimos nos adentramos en el nudo de la historia. La escena del encuentro refleja iconográficamente la confrontación social e ideológica: un grupo a cada lado, con sus respectivos popes en cabeza, los unos bien vestidos, los otros andrajosos, sucios y descalzos. El duro enfrentamiento dialéctico de ambos popes (montado en planocontraplano) expresa verbalmente el debate ideológico -religioso y político- que es el núcleo de la novela: la oposición entre el mensaje evangélico y el dogma de la iglesia, la solidaridad y el egoísmo, la miseria frente a la riqueza, la rebelión o sumisión ante el poder.

La llegada de los refugiados provoca el cisma en la comunidad griega local, que empieza a desobedecer a su pope y a ayudarlos a escondidas. El tímido Manoliós va transmutando en su personaje, Jesús, y exhortando a la solidaridad con creciente aplomo. Su metamorfosis queda simbolizada en la desaparición de su tartamudez. La escena del milagro en la montaña sustituye el pacífico sermón de las bienaventuranzas evangélico por un 
verdadero mitin político, que incita a la desobediencia: «tienen hambre y frío, tenemos que ayudarlos». Incluso el discurso del pope Grigoris («Dios es quien reparte los bienes y él creó ricos y pobres») es más político que religioso. En este punto Michalis/Juan le espeta que «si Cristo volviera a la tierra volverían a crucificarle» (frase que pone fin a la novela).

La película, sin embargo, añade un desenlace muy diferente, con escenas que recuerdan al género bélico. Todos se arman para la batalla mientras las campanas tocan a rebato. El conflicto interno adquiere dimensión interétnica cuando el pope insta al agá, que se había mantenido al margen («déjalos, los cristianos siempre se matan entre ellos») a sofocar la revuelta «antes de que se extienda la anarquía». En un último intento, el agá intenta convencer a Manoliós de que deponga las armas, pero Manoliós/Jesús no es aquí el Cristo pacifista del evangelio, que se deja inmolar, sino un líder revolucionario, y él mismo lanza el primer ataque, firmando así su sentencia de muerte.

\section{CONCLUSIONES}

En líneas generales, la película se mantiene bastante cercana a la novela, sobre todo narrativa y argumentalmente. Ambas se articulan en torno al enfrentamiento ideológico entre las dos comunidades griegas y, sobre todo, sus respectivos popes, que interpretan de manera muy diferente el mensaje evangélico. Dassin refleja esa oposición no solo verbalmente, sino también a través de la escenografía, la puesta en escena, los movimientos de cámara (planos y contraplanos, picados y contrapicados, planos generales de cada grupo y del paisaje) y el montaje. Sin embargo, el conflicto entre griegos y turcos, subyacente en toda la novela, en la película es secundario, casi anecdótico. El personaje del agá, ya retratado por Kazantzakis como un hedonista indolente, que contempla a sus súbditos griegos «como un pastor a su rebaño», es encarnado magistralmente por Grégoire Aslan como un gobernador corrupto, que prefiere contemporizar y que solo reacciona ante la presión y amenazas del propio pope.

En lo que se refiere a los personajes, la película respeta al máximo la construcción literaria, con mínimas concesiones. Por ejemplo, la viuda Katerina tiene mayor presencia que en la novela, por razones de producción (en parte comerciales). Si bien en el traslado a la pantalla se puede perder parte de la riqueza verbal de la fuente literaria, queda ampliamente compensada por la interpretación (es decir, la gestualidad) y la puesta en escena, sobre todo gracias al vestuario y la caracterización. La presencia magnética y el carisma de Melina Mercouri sirven de contrapunto perfecto al retraído Manoliós (interpretado por Pierre Vaneck). Es ella el carácter más fuerte, quien toma la iniciativa en la seducción y quien después le rechaza, es ella el acicate que él necesita para desobedecer primero y rebelarse abiertamente después y es ella quien, involuntariamente, provoca su muerte, por los celos de Panayotaros/Judas. Su pelo rubio y vestido blanco la hacen destacar sobre el resto de mujeres. El vestuario (y en menor 
medida, la caracterización) sirven también para diferenciar icónicamente a los turcos de los griegos y, entre estos, para marcar la posición social y económica. La evolución psicológica está bien reflejada en la película, aunque obviamente de forma condensada. Dassin se ha permitido una licencia al añadir una escena de fuerte carga dramática al final: la muerte de Manoliós en brazos de Katerina, que en la obra literaria desaparece mucho antes. También le adjudica un protagonismo en la revuelta posterior, imposible en la novela.

Aunque las diferencias entre una y otra son escasas, estos cambios en el final son relevantes, pues afectan al sentido y mensaje. Dassin le añade mayor carga política, apelando incluso a la revolución armada, frente a la resignación cristiana de Kazantzakis.

[Fotis]: ¿Hasta cuándo, Señor? ¿Y tu bondad? ¿Y tu justicia? No lo comprendo... Alargó la mano y acarició lenta y cariñosamente el rostro de Manoliós.

-Querido Manoliós, puede ser que hayas dado tu vida en vano murmuró-; te han matado por haber tomado sobre ti todos nuestros pecados $[\ldots]$ Y todo para impedirnos echar raíces en estas tierras... En vano, querido Manoliós, en vano te habrás sacrificado [...] En vano, Cristo amado, en vano -murmuró-; han pasado dos mil años y los hombres te siguen crucificando. ¿Cuándo nacerás, Cristo bendito, sin que seas crucificado, para vivir entre nosotros por toda la eternidad? (1963: 444445).

Mientras que Kazantzakis invita a la reflexión, Dassin invita a la acción. En la novela los refugiados, tras enterrar a Manoliós, abandonan el pueblo, antes de que lleguen los refuerzos turcos:

Instantes después, el pope Fotis, levantando la mano, dio la señal de partida:

-En el nombre de Cristo -clamó-, reemprendemos la marcha: ¡ánimo, hijos míos!

Y de nuevo, reanudaron su éxodo interminable hacia Oriente (1963: 447).

En la película, por el contrario, se levantan en armas, y acaba con ese final abierto.

Es de suponer que Kazantzakis diera su beneplácito a este giro en la historia, con el que Dassin, al parecer, pretendía «dar ánimo a las masas oprimidas» (Bien, 2000: 163) ${ }^{42}$. En ningún caso el cineasta traiciona el espíritu de la novela, la invitación a la solidaridad y a la acogida que, obviamente, comparte. Si Dassin acogió con entusiasmo la idea de trasladar al cine esta novela en concreto no fue solamente por sugerencia de Melina, sino por convicción propia. En Kazantzakis encontró una sintonía, no solo

\footnotetext{
${ }^{42}$ Bien recoge las palabras de la propia viuda del escritor, Eleni Kazantzaki.
} 
ideológica, sino también personal, con experiencias similares, como la del exilio. Es entendible que, en el momento de abordar el proyecto, Dassin estuviera más sensibilizado por las cuestiones políticas que por las religiosas y, frente a la espiritualidad de Kazantzakis, podría suscribir el escepticismo que expresa el agá ante un moribundo Patriarqueas: «qué paradoja, yo he vivido igual que tú y mi religión me promete el paraíso; tal vez ambas no son más que un cuento».

Dassin pone el foco en el enfrentamiento social, de base económica, y deja en segundo plano las diferencias religiosas, convirtiendo la representación de la Pasión, hilo conductor de la novela, casi en un Macguffin $^{43}$. De hecho, la función no se llega a celebrar. Sí mantiene la metamorfosis de los personajes, a medida que asumen la personalidad de sus equivalentes evangélicos. Pero las diferencias religiosas entre cristianos y musulmanes, las cuestiones teológicas, el desencuentro del escritor con las jerarquías eclesiásticas, no interesaban al cineasta tanto como la lucha de clases y el alegato por la libertad. En el filme la dicotomía es ricos/pobres, poderosos/sometidos: unos y otros se ayudan entre sí, al margen de sus respectivas confesiones. La resignación y el pesimismo de Kazantzakis son reemplazados por una abierta llamada a la insumisión y la lucha activa. Paradójicamente, en la vida real, Dassin había tomado el camino del exilio, como los refugiados de la novela, no como los de su película.

El cineasta también reduce la carga patriótica y nacionalista griega, un acierto que dota a la película de universalidad y permite la identificación de cualquier espectador. Convierte un conflicto local en una reflexión general sobre la libertad y la esclavitud, sobre la necesidad de una revolución, de la unión de los desfavorecidos, los parias de la tierra. Dassin plantea aquí, de nuevo, la legitimidad del uso de la violencia, de la lucha armada, para subvertir el statu quo -un tema recurrente en su filmografía-. Al igual que en Fuerza Bruta, la opresión y la injusticia acaban provocando un estallido violento.

No entraremos a discutir sobre la fidelidad ${ }^{44} \mathrm{o}$ adecuación de la película a la novela, pues la "diferencia automática" es inevitable y, por tanto, son obras artísticas independientes, con lenguajes diferentes, por más que una se base en la otra. Parece claro que el cineasta, cuya filmografía está plagada de adaptaciones literarias, no pretendía "traicionar" la obra original, dado que se entrevistó personalmente con el autor ${ }^{45}$. Por el contrario, se mantiene bastante cercano a la novela, dentro de las limitaciones de expresión, conservando cuanto era posible: tema, argumento, personajes,

${ }^{43}$ Técnica de guion para provocar un giro argumental sobre un elemento que pasa desapercibido al espectador, pero hace avanzar la acción.

${ }^{44}$ Sobre el debate de la "adaptación" de los textos literarios al cine y las diferentes escuelas de interpretación remitimos a Stam (2014) y Zecchi (2012).

45 También lo hizo con Le Breton, que, sin embargo, en principio se sintió “traicionado" por su versión de Rififi, mucho más alejada de la novela fuente que esta. 
desarrollo cronológico y narrativo, aunque introduce los cambios imprescindibles para adecuarlo al medio expresivo, dentro de su estilo personal y propósitos.

Estilísticamente sigue un modelo clásico, si bien añade un toque neorrealista, que había adoptado desde La ciudad desnuda, con figurantes no profesionales -a los que dedica unos cuantos primeros planos muy expresivos-, fotografía en blanco y negro, escenarios exteriores y un lenguaje claro y directo. La acción -y la tensión dramática- van in crescendo, desde las primeras escenas en la aldea (con la salvedad del preámbulo), casi descriptivas, la irrupción de los forasteros, los conflictos que desencadenan, hasta alcanzar el punto culminante en el violento desenlace. El final abierto es un elemento narrativo relativamente innovador, pues deja a la imaginación del espectador cómo concluirá la batalla, aunque, por otra parte, incorpora una estructura circular, con una escena final casi bélica que recuerda a la del principio.

Como hemos apuntado, Dassin omite intencionadamente referencias geográficas concretas, para dotar de mayor universalidad a la historia. Por la misma razón, atenúa la carga religiosa, mientras que acentúa el mensaje político, con un llamamiento a la unidad y a la lucha activa, que es la aportación más personal del cineasta.

El éxito de la novela no encontró correspondencia en la taquilla, como hemos dicho. Sin embargo, la mayor universalidad y trascendencia de la película le ha otorgado, con el paso del tiempo, una inesperada actualidad. Mientras que las guerras abiertas entre griegos y turcos y entre los propios griegos han quedado, afortunadamente, en el pasado, la situación política actual, la globalización, las guerras con un trasfondo religioso, el sometimiento de los pueblos, las oleadas de refugiados y sus consecuencias han devuelto a esta película su vigencia. Las nuevas posibilidades de visualización personalizada (DVD, plataformas en línea, servicio de vídeo bajo demanda VOD por streaming) nos ofrecen la oportunidad de rescatarla de un inmerecido olvido.

\section{Bibliografía CITADA}

BIEN, Peter (2000), «Nikos Kazantzakis's Novels on Film», Journal of Modern Greek Studies, 18/1, págs. 161-169 [en línea: http://muse.jhu.edu/journals/mgs/summary/v018/18.1bien.html. Fecha de consulta 13/11/2019].

KaZAnTZAKIS, Nikos (1961), Taxidévondas: Ispanía, Atenas, Kazantzaki.

KaZantZakis, Nikos (1963), Cristo de nuevo crucificado (trad. de J. L. Izquierdo Hernández), Buenos Aires, Lohlé.

López Jimeno, Amor (ed.) (2012), Las tres vidas de Jules Dassin (1911-2008).

Del cine negro al Nuevo Museo de la Acrópolis, Saarbrücken, Akademikervelag. 
STAM, Robert (2014), Teoría y práctica de la adaptación, México, Universidad Nacional Autónoma de México.

ZeCCHI, B. (ed.) (2012), Teoría y práctica de la adaptación fílmica, Madrid, Editorial Complutense.

\section{ReFEREnCias Audiovisuales}

Barco de Papel (episodio del programa radiofónico sobre literatura) [en línea: https://youtu.be/ahdCXvFXYEM. Fecha de consulta: 21/02/2020].

DAssin, Jules (1941), El corazón delator (The tell-tale heart) [cortometraje] [en línea: https://youtu.be/hAV56Lv6fdg. Fecha de consulta: 21/02/2020].

Germanós, Freddie (1976-77), Entrevista a Jules Dassin en el programa de la Televisión Pública Griega (ERT) Portraito tis Pembtis [en línea: https://archive.ert.gr/73502/. Fecha de consulta: 06/03/2020].

Kritsa Melina Merkouri [en línea: https://youtu.be/BVnzRpmfdq4. Fecha de consulta $21 / 02 / 2020]$.

Nikos Kazantzakis o las tentaciones de Ulises (documental) [en línea: https://youtu.be/C74RhNvdzuw. Fecha de consulta: 21/02/2020].

Recuerdos de los kritsenses del rodaje [en línea: https://youtu.be/DeXEu3lLg04. Fecha de consulta 21/02/2020].

Fecha de recepción: 29/05/2020.

Fecha de aceptación: 25/07/2020. 